\title{
Factors influencing the surgical decision for the treatment of degenerative lumbar stenosis in a preference-based shared decision-making process
}

\author{
Ho-Joong Kim · Jae-Young Park $\cdot$ Kyoung-Tak Kang • \\ Bong-Soon Chang $\cdot$ Choon-Ki Lee • \\ Jin S. Yeom
}

Received: 27 January 2014/Revised: 15 June 2014 / Accepted: 25 June 2014/Published online: 1 July 2014 (c) Springer-Verlag Berlin Heidelberg 2014

\begin{abstract}
Introduction In a preference-based shared decision-making system, several subjective and/or objective factors such as pain severity, degree of disability, and the radiological severity of canal stenosis may influence the final surgical decision for the treatment of lumbar spinal stenosis (LSS). However, our understanding of the shared decision-making process and the significance of each factor remain primitive. In the present study, we aimed to investigate which factors influence the surgical decision for the treatment of LSS when using a preference-based, shared decisionmaking process.

Methods We included 555 patients, aged 45-80 years, who used a preference-based shared decision-making process and were treated conservatively or surgically for chronic leg and/or back pain caused by LSS from April 2012 to December 2012. Univariate and multivariableadjusted logistic regression analyses were used to assess the association of surgical decision making with age, sex, body mass index, symptom duration, radiologic stenotic grade, Oswestry Disability Index (ODI), visual analog
\end{abstract}

H.-J. Kim · J.-Y. Park · J. S. Yeom ( $\square)$

Spine Center and Department of Orthopaedic Surgery, Seoul National University College of Medicine and Seoul National University Bundang Hospital, 166 Gumiro, Bundang-gu, Seongnam 463-707, Republic of Korea

e-mail: highcervical@gmail.com

\section{K.-T. Kang}

Department of Mechanical Engineering, Yonsei University, 134 Shinchon-dong, Seodaemun-gu, Seoul, Republic of Korea

B.-S. Chang · C.-K. Lee

Department of Orthopaedic Surgery, Seoul National University College of Medicine and Seoul National University Hospital, 101 Daehangno, Jongno-gu, Seoul 110-744, Republic of Korea scale (VAS) scores for back and leg pain, Short Form-36 (SF-36) subscales, and motor weakness.

Results In univariate analysis, the following variables were associated with a higher odds of a surgical decision for LSS: male sex; the VAS score for leg pain; ODI; morphological stenotic grades $\mathrm{B}, \mathrm{C}$, and $\mathrm{D}$; motor weakness; and the physical function, physical role, bodily pain, social function, and emotional role of the SF-36 subscales. Multivariate analysis revealed that male sex, ODI, morphological stenotic grades $\mathrm{C}$ and $\mathrm{D}$, and motor weakness were significantly associated with a higher possibility of a surgical decision.

Conclusion Motor weakness, male sex, morphological stenotic grade, and the amount of disability are critical factors leading to a surgical decision for LSS when using a preference-based shared decision-making process.

Keywords Degenerative lumbar spinal stenosis . Preference-based decision making - Shared decision making $\cdot$ Surgical decision

\section{Introduction}

Patient preference causes a substantial variation in the care of degenerative spinal disease [1-3]. Therefore, the interest in improving the decision-making process based on patient preference has been recently renewed $[1,4]$. In a paternalistic patient-doctor relationship, physicians make the treatment decisions; however, in a preference-based shared decision-making process, the healthcare provider helps to educate the patient, to ensure that they have the knowledge required to understand the pros and cons of the various treatment options. The provider then helps the patient to explore their preferences, and the patient chooses the 
treatment that best conforms to their values $[1,5,6]$. Therefore, given that all treatment options for degenerative spinal disease have limited effectiveness and well-known risks, the communication and shared decision-making process involving the patient and doctor are of critical importance, not only for making a suitable surgical decision but also for increasing the patient's satisfaction with the surgical outcome [7].

In the case of degenerative lumbar spinal stenosis (LSS), a previous study showed that a younger age, worse bodily pain, worse physical functioning, worse Oswestry Disability Index (ODI), and lateral recess stenosis may be predictors for surgical treatment decisions [8]. Therefore, several subjective and/or objective factors such as pain severity, degree of disability, and the radiological severity of canal stenosis may influence the final surgical shared decision-making process. However, our understanding of the shared decision-making process and the significance of each influencing factor remain primitive. In the present study, we aimed to clarify the significance of each influencing factor on the surgical decision for the treatment of LSS when using a preference-based shared decision-making system.

\section{Patients and methods}

Study design and study population

The hospital's institutional review board approved the study. We collected data on consecutive patients. All data including questionnaires and physical examinations were routinely obtained as part of the routine care of patients with lumbar stenosis or were obtained from their medical records, even though the study was prospectively planned. Therefore, the institutional review board did not require that the patients should provide informed consent. The patients included were aged between 45 and 80 years, had received conservative or surgical treatment between April 2012 and December 2012 for chronic leg or back pain, and had walking intolerance due to neurogenic claudication caused by degenerative LSS. The LSS was diagnosed when one or more of the following symptoms were present with radiological central or lateral recess stenotic lesions in the lumbar spine [9]: pain, neurological deficits in the lower extremities and buttocks, and bladder or bowel dysfunction. The characteristic symptoms were induced or exacerbated with walking or prolonged standing and relieved in the lumbar flexion, sitting, or recumbent position. The following were the exclusion criteria: foraminal or extraforaminal stenosis without central or lateral recess stenosis, a history of psychiatric disorders or peripheral vascular disease, any concurrent serious medical condition causing disability, or a general health status including sepsis or cancer. Cases with foraminal and extraforaminal stenosis were excluded as this stenosis cannot be graded by Schizas' classification. Furthermore, cases with psychiatric disorders, peripheral vascular disease, and any concurrent serious medical condition were excluded because these conditions could influence the ODI and general health status. We assessed 642 patients for eligibility, and 555 patients who met the inclusion and exclusion criteria were included in the study.

A detailed medical history and physical examination, analysis of the lumbar MRI scans, and completion of a series of questionnaires, which included the ODI (version 2.0), visual analog scale (VAS) for back pain and leg pain, and the Short Form-36 (SF-36), were performed for all patients before any treatment was provided as part of routine care. If the patient initially had decided to receive conservative treatment but subsequently chose surgical treatment during the follow-up period, a series of questionnaires, such as the ODI, VAS for back pain and leg pain, and SF-36, were re-administered before the surgery.

Data collection and analysis

The ODI is a self-administered questionnaire measuring back-specific function on a 10 -item scale, each with six response categories. Each item is scored from 0 to 5, and the summation of each item is transferred to a $0-100$ scale. There is no unit of outcome and no established value for a specific health status or change in health status [10]. The average levels of back and leg pain were assessed using the VAS, which comprises a bar with "none" on one end $(0)$ of a 10-cm line and "disabling pain" on the other end of the bar (10). The patients placed a mark on the $10-\mathrm{cm}$ line to indicate their VAS score for back pain and leg pain, and the distance $(\mathrm{cm})$ of the mark from the zero point was recorded as the score. General health status was assessed using the language-specific and validated SF-36. The raw scores for the eight subscales and the two summaries of the SF-36 [physical function (PF), role physical (RP), bodily pain (BP), general health $(\mathrm{GH})$, vitality (VT), social function (SF), role emotion (RE), and mental health (MH), as well as physical component summary (PCS) and mental component summary (MCS)] were transferred to a norm-based scoring system [11].

Making a preference-based shared decision

Shared decision making is a collaboration between the patient and surgeon that engages the patient in the process of making a decision regarding conservative treatment or surgical treatment for LSS [4]. This is markedly different from the informed consent process. The elements of 
informed consent include the disclosure of the nature of the intervention, pros and cons of the intervention, alternatives to the intervention, and pros and cons of the alternatives, followed by an explicit patient agreement or refusal about the suggested treatment option. However, shared decision making requires an informed choice from the patient - the clinician informs the patient about the options, along with all the necessary and available information about the treatments and outcomes, and the patient chooses the treatment based on his/her preferences (Table 1).

At the first visit, the treatment plan for degenerative LSS was formulated using the shared decision-making process and began with patient education, which was provided by the first author. The patient was educated about his/her current status of degenerative LSS and the available

Table 1 The shared decision making and informed consent processes for making a decision regarding the treatment for LSS

\begin{tabular}{|c|c|c|}
\hline & $\begin{array}{l}\text { Shared } \\
\text { decision } \\
\text { making }\end{array}$ & $\begin{array}{l}\text { Informed } \\
\text { consent }\end{array}$ \\
\hline The natural history of LSS & $\mathrm{O}$ & $\mathrm{O}$ \\
\hline $\begin{array}{l}\text { Information about the reasonable options } \\
\text { at a level at which the patient will } \\
\text { understand }\end{array}$ & $\mathrm{O}$ & $\mathrm{O}$ \\
\hline Pros and cons of conservative treatment & $\mathrm{O}$ & $\mathrm{O}$ \\
\hline Pros and cons of surgical treatment & $\mathrm{O}$ & $\mathrm{O}$ \\
\hline $\begin{array}{l}\text { Surgeon suggests the treatment option/ } \\
\text { patient agrees or refuses }\end{array}$ & $\mathrm{X}$ & $\mathrm{O}$ \\
\hline $\begin{array}{l}\text { The patient's understanding is assessed, } \\
\text { and the patient chooses the treatment } \\
\text { option }\end{array}$ & $\mathrm{O}$ & $\mathrm{X}$ \\
\hline
\end{tabular}

treatment options using a standardized booklet. Furthermore, his/her own MRI scan was shown, and a description of the stenotic grade was provided. Finally, the patient was informed about the evidence supporting the advantages and disadvantages of each available treatment option from well-designed studies on LSS [12-15]. This process took an average of $10 \mathrm{~min}$. After the education stage, we assessed whether the patient completely understood the information and had knowledge about the condition and treatment options. The patient was asked to describe the decision-making process, the pros and cons of the various treatment options, and whether the treatment decision made was congruent with her/his preferences (Fig. 1). Thus, the shared decision-making process was based on the patient's preference and routinely involved a collaborative effort between the patient and the surgeon when choosing between conservative and surgical treatment. During the follow-up period, the patient had the option to change the treatment from non-surgical to surgical.

Radiological analysis

Radiological analysis using the MRI findings was performed by an independent observer who was blinded to the purpose of this study. The grading of canal stenosis was based on the cerebrospinal fluid (CSF)/rootlet ratio as seen on axial T2 images, according to the method by Schizas et al. [16]. If the patient had canal stenosis at multiple levels, the most stenotic level was used for grading. The description of the grading is as follows. Grade A stenosis denotes clearly visible CSF inside the dural sac with nonhomogenous distribution. A1 indicates that the rootlets lie dorsally and occupy less than half of the dural sac area. A2
Fig. 1 The process of preference-based shared decision making

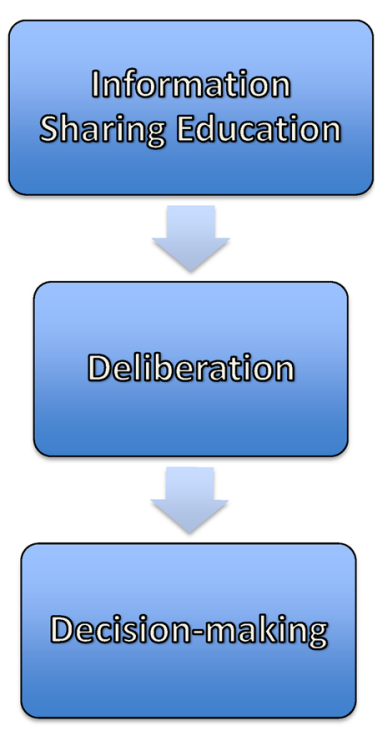

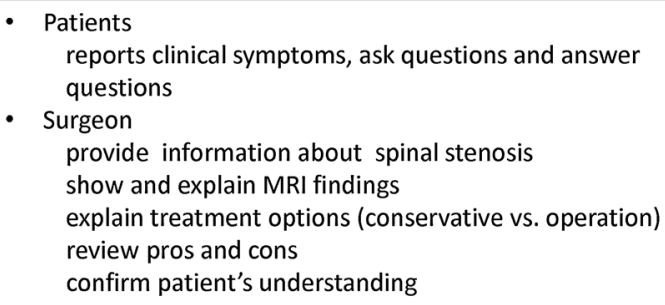

- Review treatment options (medication, physical therapy, epidural steroid injection, and surgery)

- Discuss patient's preference and specific concerns about treatment option 
suggests that the rootlets lie dorsally in contact with the dura but in a horseshoe configuration. A3 indicates that the rootlets lie dorsally and occupy more than half of the dural sac area. A4 suggests that the rootlets lie centrally and occupy the majority of the dural sac area. Grade B stenosis indicates that the rootlets occupy the entire dural sac but can still be individualized; in such cases, some CSF is still present, giving the sac a grainy appearance. Grade C stenosis suggests that no rootlets can be recognized, the dural sac demonstrates a homogeneous gray signal with no visible CSF signal, and the epidural fat is present posteriorly. Grade D stenosis indicates that there is no posterior epidural fat and no rootlets are recognizable.

\section{Statistical analysis}

Independent variables of interest that were assessed for their associations with the surgical treatment and the patients' subjective symptoms and/or objective findings included age, sex, body mass index (BMI), symptom duration, radiologic stenotic grade, ODI, VAS score for back pain and leg pain, SF-36 subscales, and motor weakness. Among these, age, ODI, VAS score, and the SF36 subscales were treated as continuous variables. For the surgical treatment of degenerative LSS, the odds ratio of each variable was calculated using univariate logistic regression analysis and multivariate logistic regression analysis. First, univariate analyses were performed for all expected variables related to the surgical decision. The variables that were significantly associated with surgical treatment at $P<0.10$ in univariate analysis were entered into the multivariate model, along with potentially important variables such as age, BMI, and sex, regardless of statistical significance. For the multivariate models, we anticipated a potential issue of collinearity between the variables and set an a priori rule to exclude variables with correlation coefficients of $\geq 0.50$. The $\alpha$ level was set at 0.05 for significance. All statistical analyses were performed using the SPSS, version 20.0.0 statistical software package (SPSS, Inc., Chicago, IL, USA).

\section{Results}

Study population characteristics

Of the 555 patients, 170 patients underwent surgical treatment during the follow-up period. The remaining 385 patients did not undergo spinal surgery during the followup period. Table 2 describes the detailed baseline characteristic and clinical findings. Sixty-seven patients initially received conservative treatment and subsequently opted for surgery. The average period during which they received
Table 2 Study population characteristics

\begin{tabular}{ll}
\hline$N$ & 555 patients \\
Age (years) & $65.9(11.1)$ \\
Male: female $(\%)$ & $29: 71$ \\
BMI $\left(\mathrm{kg} / \mathrm{cm}^{2}\right)$ & $25.1(4.1)$ \\
Symptom duration & $15.2(8.1)$ months \\
Morphological stenosis grade & \\
Grade A & 188 patients $(34 \%)$ \\
Grade B & 116 patients $(21 \%)$ \\
Grade C & 198 patients $(36 \%)$ \\
Grade D & 53 patients $(9 \%)$ \\
Treatments & Conservative: 385 patients \\
& Surgical treatments: 170 patients \\
\hline
\end{tabular}

Values are presented as mean values (standard deviation)

conservative treatment was 3.3 months. The initial average ODI score (standard deviation) of these patients was 43.2 (15.4), which was higher than that of patients in the conservative group [37.0 (13.9)]. After opting for surgery, the average ODI score was 45.6 (12.5) in these patients.

Univariate analysis of the predictors for surgical decision making

Male sex; VAS score for leg pain; ODI; and the PF, RP, $\mathrm{BP}, \mathrm{SF}$, and RE subscales of the SF-36 were each associated with a higher odds for a decision to surgically treat LSS (Table 3). The morphological stenotic grades B, C, and D demonstrated approximately 2.7, 2.3, and 5.4 times higher odds of a surgical decision compared to the stenotic grades $\mathrm{A}, \mathrm{B}$, and $\mathrm{C}$, respectively. Furthermore, motor weakness was associated with approximately 26.1 times higher odds of surgical treatment for LSS. However, age, BMI, and VAS score for back pain did not differ between the surgical and non-surgical groups (Table 3).

Multivariate analysis of the predictors for surgical decision making

The correlation coefficients $(R)$ were as follows: age and VAS score for back pain, $R=0.096$; age and VAS score for leg pain, $R=0.021$; age and ODI, $R=0.122$; VAS score for leg pain and ODI, $R=0.353$; and RE and ODI, $R=-0.309$. These variables were included in the multivariable models on the basis of both significance in the univariate models and lack of collinearity. However, the correlation coefficients between the ODI and PF, RP, BP, and SF subscores of the SF-36 were $>0.5$. Therefore, only the ODI scores were included in the multivariate analysis model. Furthermore, in both the surgical and non-surgical groups, there were no differences in the VAS score and ODI in relation to the morphologic stenosis grade (Fig. 2a, b). 
Table 3 Univariate analysis of the predictors of surgical treatment for LSS

\begin{tabular}{|c|c|c|c|c|c|}
\hline & $\mathrm{PF}$ & $31.4(11.1)$ & $26.2(9.5)$ & $0.950(0.922-0.978)$ & 0.001 \\
\hline \multirow{3}{*}{$\begin{array}{l}\text { Values are presented as mean } \\
\text { (standard deviation) or numbers } \\
(\%)\end{array}$} & $\mathrm{RP}$ & $32.4(11.7)$ & $28.9(9.4)$ & $0.965(0.937-0.995)$ & 0.020 \\
\hline & $\mathrm{BP}$ & $32.4(8.9)$ & $29.2(7.8)$ & $0.953(0.919-0.988)$ & 0.009 \\
\hline & GH & $36.7(11.6)$ & $38.0(10.1)$ & $1.012(0.984-1.041)$ & 0.394 \\
\hline \multirow{2}{*}{$\begin{array}{l}\text { Bold means statistical } \\
\text { significant value }\end{array}$} & VT & $41.2(11.9)$ & $41.0(10.2)$ & $0.999(0.971-1.027)$ & 0.918 \\
\hline & SF & $38.3(13.4)$ & $33.3(12.6)$ & $0.970(0.947-0.993)$ & 0.010 \\
\hline \multirow{7}{*}{$\begin{array}{l}O D I \text { Oswestry Disability Index, } \\
P F \text { physical function, } R P \text { role of } \\
\text { physical, } B P \text { bodyily pain, } G H \\
\text { general health, } V T \text { vitality, } S F \\
\text { social function, } R E \text { role of } \\
\text { emotion, } M H \text { mental health, } \\
P C S \text { physical component } \\
\text { summary, } M C S \text { mental } \\
\text { component summary }\end{array}$} & $\mathrm{RE}$ & $38.2(16.7)$ & $32.2(16.2)$ & $0.978(0.960-0.996)$ & 0.017 \\
\hline & $\mathrm{MH}$ & $39.6(12.5)$ & $38.1(11.8)$ & $0.990(0.965-1.015)$ & 0.411 \\
\hline & PCS & $30.0(11.7)$ & $28.5(8.7)$ & $0.984(0.953-1.015)$ & 0.309 \\
\hline & MCS & $40.2(17.4)$ & $39.9(13.0)$ & $0.998(0.978-1.019)$ & 0.873 \\
\hline & Radiological stenotic grade & & & & \\
\hline & $\mathrm{A}$ & $169(44 \%)$ & $19(11 \%)$ & 1 & 0.024 \\
\hline & $\mathrm{B}^{\mathrm{a}}$ & $89(23 \%)$ & $27(16 \%)$ & $2.698(1.422-5.120)$ & 0.001 \\
\hline \multirow{2}{*}{$\begin{array}{l}\text { a Odds compared to grade A } \\
\text { stenosis }\end{array}$} & $\mathrm{C}^{\mathrm{b}}$ & $116(30 \%)$ & $82(48 \%)$ & $2.330(1.392-3.900)$ & 0.001 \\
\hline & $\mathrm{D}^{\mathrm{c}}$ & $11(3 \%)$ & $42(25 \%)$ & $5.401(2.625-11.113)$ & \\
\hline \multirow{2}{*}{$\begin{array}{l}\text { b Odds compared to grade B } \\
\text { stenosis }\end{array}$} & Motor weakness & & & & \\
\hline & None & $382(99 \%)$ & $141(83 \%)$ & 1 & \\
\hline c Odds compared to grade $\mathrm{C}$ & Deficit & $3(1 \%)$ & $29(17 \%)$ & $26.189(7.822-87.322)$ & $<0.001$ \\
\hline
\end{tabular}

Multivariate analysis revealed that male sex, ODI, morphological stenotic grades $\mathrm{C}$ and $\mathrm{D}$, and motor weakness were significantly associated with a higher odds of a surgical decision (Table 4) (Fig. 3). However, age, RE of the SF-36 subscales, VAS score for leg pain, and morphological stenotic grade B were not predictive factors for a surgical decision.

\section{Discussion}

It should be noted that the current study was performed using data from a single institute and a single spine surgeon. This is a significant limitation of the present study. Hence, given the variation of surgical indications, techniques, and methods [3, 17], the present findings are not generalizable to the population at large. However, the current study is based on the setting of preference-based shared decision making. We acknowledge that, in preference-based care, the treatment decision-making process depends on neither the physician nor the surgeon but rather on good communication between the doctor and the patient [6]. Therefore, the current results provide relevant information on the shared decision-making system for degenerative LSS.

Intuitively, severe leg pain and functional disability may influence the surgical decision making, and this hypothesis was proven in both the present study and earlier studies [8, $14,15]$. However, with regard to age, the current results contrast with those of a previous study. There was no difference in age between the surgical and non-surgical group in the current study; however, Kurd et al. [8] demonstrated that younger patients are more likely to choose surgery than older patients. We believe that the lack of an age difference between the surgical and non-surgical groups in the present study resulted from the social and 
Fig. 2 Comparison of the Oswestry Disability Index and the visual analog scale score for leg pain in relation to the morphological stenosis grade in both the non-surgical and surgical groups. a Non-surgical group. b Surgical group

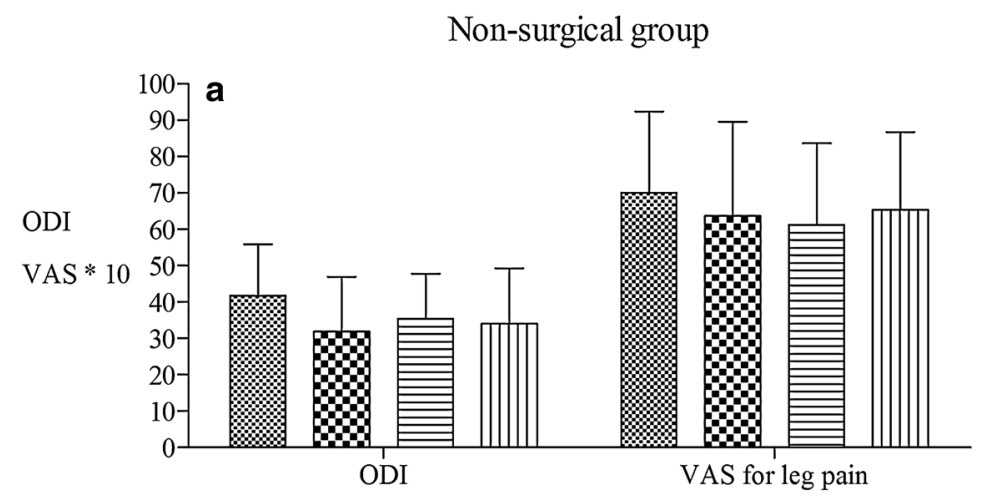

Group A stenosis

0 Group B stenosis

E Group C stenosis

س] Group D stenosis

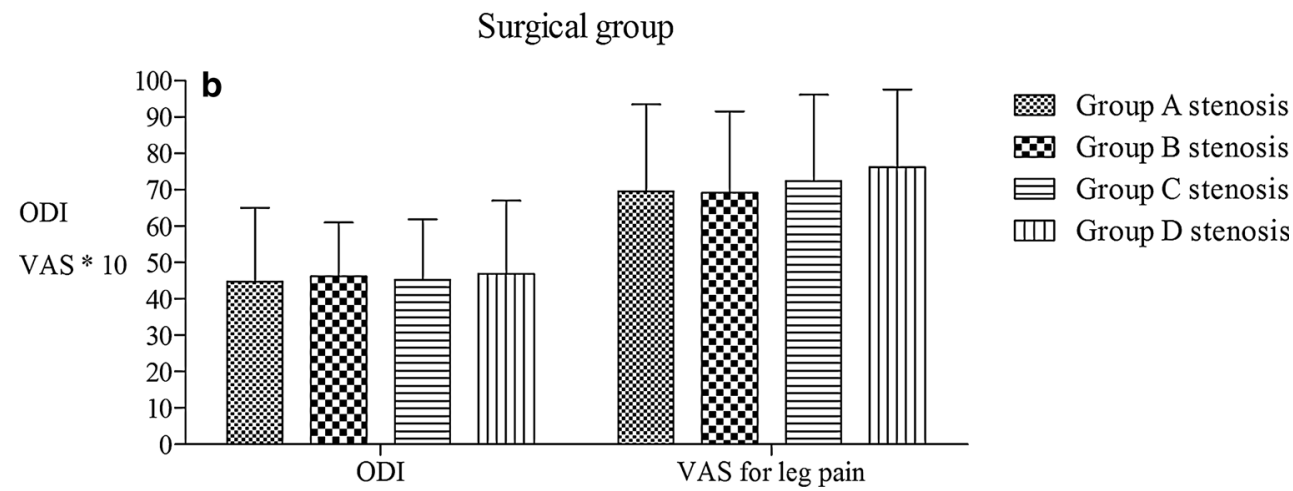

Table 4 Multivariate analysis of the predictors of surgical decision making of LSS

\begin{tabular}{|c|c|c|}
\hline & Odds ratio (95\% confidence interval) & $P$ value \\
\hline Age (years) & $0.967(0.931-1.004)$ & 0.082 \\
\hline \multicolumn{3}{|l|}{ Sex } \\
\hline Male & 1 & 0.021 \\
\hline Female & $0.635(0.463-0.871)$ & \\
\hline \multicolumn{3}{|l|}{ VAS score } \\
\hline Leg pain & $1.114(0.939-1.323)$ & 0.216 \\
\hline ODI & $1.092(1.027-1.161)$ & 0.005 \\
\hline SF-36 RE & $0.980(0.956-1.005)$ & 0.111 \\
\hline \multicolumn{3}{|c|}{ Radiological stenotic } \\
\hline \multicolumn{3}{|l|}{ Grade } \\
\hline A & 1 & 0.106 \\
\hline B & $2.392(0.830-6.897)$ & 0.003 \\
\hline $\mathrm{C}^{\mathrm{a}}$ & $2.353(1.250-4.429)$ & 0.002 \\
\hline $\mathrm{D}^{\mathrm{b}}$ & $3.473(2.370-5.090)$ & \\
\hline \multicolumn{3}{|c|}{ Motor weakness } \\
\hline None & 1 & 0.037 \\
\hline Deficit & $10.173(4.237-24.425)$ & \\
\hline
\end{tabular}

Bold means statistical significant value

$O D I$ Oswestry Disability Index, $R E$ role of emotion

a Odds compared to grade B stenosis

${ }^{\mathrm{b}}$ Odds compared to grade $\mathrm{C}$ stenosis

cultural environment and the insurance system. The nation in which the present study was conducted provides national health insurance equally to all people regardless of profession or age. Therefore, access to surgical treatment for older patients does not differ from younger ones, which may partially explain why there was no age difference between the two groups in the present study. The Maine Lumbar Spine Study similarly reported no difference in age between the surgical and non-surgical groups [15].

In multivariate logistic regression analysis, the ODI scores, which are related to the patients' symptoms, were significantly associated with higher odds of a surgical decision; however, the VAS score for the leg was not significantly associated with higher odds of a surgical decision. This finding implies that the actual restriction of daily life is a more important factor for a surgical decision than radiating leg pain or claudication per se. Although subjective patient pain may be correlated with disability ( $R=0.353, P<0.001)$, it can be presumed that patients with degenerative LSS considered the inability to perform daily activities as more important than leg pain with claudication when making a surgical decision, given that the ODI is basically a subjective self-reported questionnaire on condition-specific disabilities [10].

The present study also demonstrated that female sex was a significant factor that negatively influenced surgical decisions for the treatment of degenerative LSS. Female patients were significantly more likely to choose conservative treatment for degenerative LSS. This finding seems to be in contrast with that of earlier reports, in which female patients presenting with lower back pain and 
Fig. 3 Multivariate logistic regression analysis of the factors influencing surgical decision making. Male sex, Oswestry Disability Index, morphological stenotic grades $\mathrm{C}$ and $\mathrm{D}$, and motor weakness were independent predictors of a surgical decision for treating lumbar stenosis (the odds of the morphological stenotic grades $\mathrm{C}$ and $\mathrm{D}$ were described, compared to the next lower grade of stenosis, B and C, respectively)

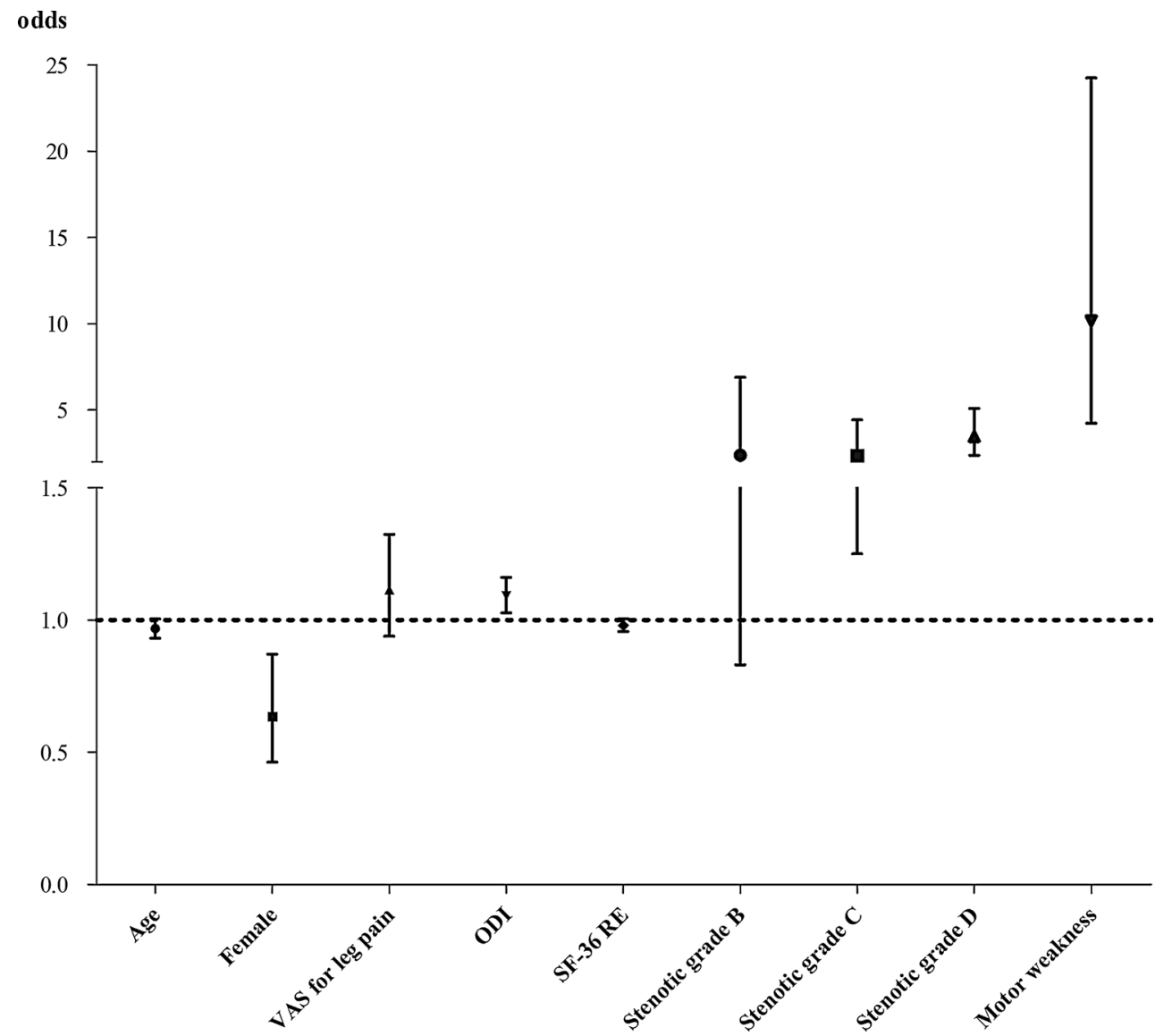

radiating leg pain appeared to undergo spinal surgery more frequently than male patients $[18,19]$. Other studies have also reported that the prevalence of musculoskeletal pain and low back pain is higher in women than in men [20,21]. This difference has been explained by biological and psychosocial mechanisms, including differences in pain perception, coping mechanisms, and hormones [22, 23]. However, the higher pain intensity and surgical rates of LSS do not always mean that female patients prefer surgical treatment. One study's findings corroborate this finding, as it reported a significantly different willingness to accept surgical risks between the sexes [24]. Since women were reported as being more fearful of surgery and preferred to suffer arthritis pain rather than risk surgery [1, 24], women delayed surgery to await a better technology and to also avoid disrupting caregiving roles for dependent spouses and other family members [24]. The higher rate of lumbar surgery in women may not be attributed to preference but rather to their higher pain sensitivity and increased pain perception.

Stenosis of the lumbar spine was radiologically graded using the method of Schizas et al. [16]. Stenotic grade was significantly associated with the highest odds of a surgical decision. In particular, grade $\mathrm{C}$ had approximately a 2.4 times higher odds of surgical treatment compared to grade B, whereas grade D had approximately a 3.4 times higher odds of surgical treatment compared to grade $\mathrm{C}$. This finding is consistent with that of a previous study in which spine surgeons mostly agreed that grades $C$ and $D$ were the morphological grades associated with decompressive surgery [25]. However, another study showed no significant difference in stenosis severity between the surgical and non-surgical groups [8]. This difference may potentially be associated with the shared decision-making process. That is, the significant odds of stenosis severity in the shared surgical decision-making setting of this study may be explained by the fact that the patients may have noted the radiological severity when they were shown their MRI scans. Furthermore, as expected, patients with motor weakness deficits had a tenfold higher chance of surgical treatment compared to those without it. The high odds ratios of morphological stenosis grades $\mathrm{C}$ and $\mathrm{D}$ and motor weakness for a surgical decision support the fact that the decision to proceed with surgery for LSS was primarily based on the morphology of the dural sac with motor weakness, even though it may be influenced by several other factors, such as clinical symptoms, finances, and access to health resources [16, 25]. In addition, considering 
that there was no correlation between ODI and the radiologic stenotic grade in the present study and earlier studies $[16,26]$, the morphological stenotic grade may independently influence the shared decision-making process, leading to surgery.

There are several limitations to this study. First, the patients' income or wealth was not assessed, which can influence the accessibility for treatment. However, as mentioned earlier, the nation in which the study was conducted in provides national health insurance equally to all people and has no racial diversity. Nevertheless, since preference disparities caused by differences in literacy and patient knowledge remained [5], the current findings should be interpreted cautiously due to the potential racial, ethnic, and sex preference-related disparities. Second, although patients with a serious comorbidity or medical condition were excluded, a measure of the comorbidity, such as the American Society of Anesthesiologists' grade, might have provided important information. Third, the present study would also have benefited from the inclusion of a control group that did not receive any educational information, which would have enabled us to investigate whether the shared decision making accounts for any difference compared to the paternalistic patient-doctor relationship. Lastly, the unequal gender distribution in the present cohort is another limitation that may influence our findings.

In conclusion, this study indicates the critical factors leading to a surgical decision for the treatment of degenerative LSS when using a preference-based shared decision-making process. Motor weakness, the subjective amount of disability of daily activity, and Schizas grades C and $\mathrm{D}$ are associated with a higher odds of a surgical decision. Moreover, women with LSS are more likely to opt for conservative treatment than men.

Acknowledgments This study is not supported by any funding source.

Conflict of interest The authors have no conflict of interest to declare.

\section{References}

1. Katz JN (2001) Patient preferences and health disparities. JAMA J Am Med Assoc 286(12):1506-1509

2. Hawker GA, Wright JG, Coyte PC, Williams JI, Harvey B, Glazier R, Wilkins A, Badley EM (2001) Determining the need for hip and knee arthroplasty: the role of clinical severity and patients' preferences. Med Care 39(3):206-216

3. Bederman SS, Coyte PC, Kreder HJ, Mahomed NN, McIsaac WJ, Wright JG (2011) Who's in the driver's seat? The influence of patient and physician enthusiasm on regional variation in degenerative lumbar spinal surgery. Spine 36(6):481-489. doi:10. 1097/BRS.0b013e3181d25e6f
4. Ridd M, Shaw A, Lewis G, Salisbury C (2009) The patient doctor relationship: a synthesis of the qualitative literature on patients' perspectives. Br J Gen Pract 59(561):e116-e133. doi:10.3399/ bjgp09X420248

5. Kaplan R (1999) Shared medical decision-making: a new paradigm for behavioral medicine-1997 presidential address. Ann Behav Med 21(1):3-11. doi:10.1007/BF02895027

6. Weinstein JN (2000) The missing piece: embracing shared decision making to reform health care. Spine (Philadelphia, Pa 1976) 25(1):1-4

7. Deyo RA, Cherkin DC, Weinstein J, Howe J, Ciol M, Mulley AG (2000) Involving patients in clinical decisions: impact of an interactive video program on use of back surgery. Med Care 38(9):959-969

8. Kurd M, Lurie J, Zhao W, Tosteson T, Hilibrand A, Rihn J, Albert T, Weinstein J (2012) Predictors of treatment choice in lumbar spinal stenosis: a spine patient outcomes research trial study. Spine (Philadelphia, Pa 1976) 37(19):1702-1707

9. Watters WC 3rd, Baisden J, Gilbert TJ, Kreiner S, Resnick DK, Bono CM, Ghiselli G, Heggeness MH, Mazanec DJ, O'Neill C, Reitman CA, Shaffer WO, Summers JT, Toton JF, North American Spine S (2008) Degenerative lumbar spinal stenosis: an evidence-based clinical guideline for the diagnosis and treatment of degenerative lumbar spinal stenosis. Spine J 8(2):305-310. doi: $10.1016 /$ j.spinee.2007.10.033

10. Fairbank JC, Pynsent PB (2000) The Oswestry Disability Index. Spine (Philadelphia, Pa 1976) 25(22):2940-2952

11. Ware J, Snow K, Kosinski M, Gandek B (1993) SF-36 health survey manual and interpretation guide. New England Medical Center, The Health Institute, Boston

12. Weinstein JN, Tosteson TD, Lurie JD, Tosteson AN, Blood E, Hanscom B, Herkowitz H, Cammisa F, Albert T, Boden SD, Hilibrand A, Goldberg H, Berven S, An H (2008) Surgical versus nonsurgical therapy for lumbar spinal stenosis. N Engl J Med 358(8):794-810

13. Weinstein JN, Tosteson TD, Lurie JD, Tosteson A, Blood E, Herkowitz H, Cammisa F, Albert T, Boden SD, Hilibrand A, Goldberg H, Berven S, An H (2010) Surgical versus nonoperative treatment for lumbar spinal stenosis 4-year results of the spine patient outcomes research trial. Spine (Phila Pa 1976) 35(14):1329-1338. doi:10.1097/BRS.0b013e3181e0f04d

14. Atlas SJ, Keller RB, Robson D, Deyo RA, Singer DE (2000) Surgical and nonsurgical management of lumbar spinal stenosis: 4-year outcomes from the maine lumbar spine study. Spine (Philadelphia, Pa 1976) 25(5):556-562

15. Atlas S, Keller R, Wu Y, Deyo R, Singer D (2005) Long-term outcomes of surgical and nonsurgical management of lumbar spinal stenosis: 8 to 10 year results from the maine lumbar spine study. Spine (Philadelphia, Pa 1976) 30(8):936-943

16. Schizas C, Theumann N, Burn A, Tansey R, Wardlaw D, Smith FW, Kulik G (2010) Qualitative grading of severity of lumbar spinal stenosis based on the morphology of the dural sac on magnetic resonance images. Spine (Philadelphia, Pa 1976) 35(21):1919-1924

17. Weinstein JN, Lurie JD, Olson PR, Bronner K, Fisher ES (2006) United States' trends and regional variations in lumbar spine surgery: 1992-2003. Spine (Philadelphia, Pa 1976) 31(23):2707-2714

18. Jacobs JJ, Andersson GBJ, Bell JE et al (2008) The burden of musculoskeletal diseases in the United States: prevalence, societal and economic cost. American Academy Orthopedic Surgeons Rosemont. http://www.boneandjointburden.org

19. Strömqvist F, Ahmad M, Hildingsson C, Jönsson B, Strömqvist B (2008) Gender differences in lumbar disc herniation surgery. Acta Orthop 79(5):643-649

20. Brattberg G, Parker MG, Thorslund M (1997) A longitudinal study of pain: reported pain from middle age to old age. Clin J Pain 13(2):144-149 
21. Lavsky Shulan M, Wallace RB, Kohout FJ, Lemke JH, Morris MC, Smith IM (1985) Prevalence and functional correlates of low back pain in the elderly: the Iowa $65+$ Rural Health Study. J Am Geriatr Soc 33(1):23-28

22. Fillingim RB, King CD, Ribeiro Dasilva MC, Rahim Williams B, Riley JL (2009) Sex, gender, and pain: a review of recent clinical and experimental findings. J Pain 10(5):447-485

23. Racine M, Tousignant Laflamme Y, Kloda LA, Dion D, Dupuis G, Choinière M (2012) A systematic literature review of 10 years of research on sex/gender and pain perception-part 2: do biopsychosocial factors alter pain sensitivity differently in women and men? Pain 153(3):619-635
24. Karlson EW, Daltroy LH, Liang MH, Eaton HE, Katz JN (1997) Gender differences in patient preferences may underlie differential utilization of elective surgery. Am J Med 102(6):524-530

25. Schizas C, Kulik G (2012) Decision-making in lumbar spinal stenosis: a survey on the influence of the morphology of the dural sac. J Bone Jt Surg Br 94(1):98-101

26. Kim HJ, Suh BG, Lee DB, Lee GW, Kim DW, Kang KT, Chang BS, Lee CK, Yeom JS (2013) The influence of pain sensitivity on the symptom severity in patients with lumbar spinal stenosis. Pain Physician 16:135-144 